\title{
Situació Actual del \\ Tennis Femení a \\ Espanya
}

\section{Montserrat Francín i Veciana ${ }^{a}$}

\author{
Data de defensa: 15/06/2012
}

Paraules clau: tennis femení, motivació, entrenament, preparació física, components tennis i preparació psicològica.

\section{Justificació}

La motivació envers aquesta investigació neix de la implicació en la pràctica i l'ensenyament d'aquest esport i, a la vegada, del desig d'esbrinar les dificultats que el tennis femení pateix actualment i les raons que frenen, en el marc concret de l'estat espanyol, l'assoliment dels primers llocs en la classificació mundial i la manca de referents o models de noies que facilitin i incentivin el camí cap a la professionalització. Darrerament, en totes les conferències i clínics ${ }^{1}$ als quals he assistit, sempre s'ha posat damunt la taula la situació del tennis femení; fins i tot s'ha parlat d'una "crisi en aquesta modalitat esportiva". Això ha suscitat en mi un interès per conèixer la realitat d'aquest esport des de la vessant dels tècnics i de les jugadores, que en definitiva són els grans protagonistes d'aquesta situació.

Abans d'endinsar-nos en aquest estudi sobre l'esport femení en l'àmbit semiprofessional i de posar damunt la taula l'estat actual de la qüestió, considerem necessari establir un marc introductori de referència on situar les nostres investigacions; a la vegada, cal exposar les motivacions que ens han dut a caminar per un terreny on serà fonamental contraposar les estadístiques sobre el rendiment o els objectius assolits amb l'eficàcia i la idoneïtat dels mètodes, paràmetres i recursos destinats a l'aprenentatge.

El nostre estudi es centrarà en l'esport del tennis i més concretament, en la modalitat femenina en el seu àmbit semiprofessional; això vol dir, aquella etapa on es troben gran nombre de jugadores amb el propòsit, hem de suposar, de donar un salt qualitatiu que els hauria de permetre (donant per fet que parlem d'un collectiu amb unes condicions físiques idònies), entrar a formar part del món professional d'aquest esport. Aquesta etapa, no obstant això, es converteix en un espai bellugadís que

\footnotetext{
${ }^{a}$ Institut Francesc Vidal i Barraquer - Tarragona
} 
moltes esportistes acaben abandonant. Ens interessa especialment esbrinar i analitzar a fons les diferents raons que desencadenen l'esmentada renúncia, o bé les que tenen com a conseqüència la impossibilitat d'accedir a la professionalització. Es tractarà doncs d'anar més enllà de les hipòtesis que de bon principi ja podríem formular; perquè, òbviament, pretenem anar més enllà de centrar el nostre discurs en la manca de projecció o bé l'excessiva competència, i considerar aquestes variants com les úniques que condueixen al desencant, a la desil.lusió i/o a l'absència de resultats rellevants.

A més a més d'entrar de ple en les qüestions de fons sobre el desencís, la competitivitat i l'adequació dels paràmetres dels tècnics (sovint homes) a les necessitats i dificultats d'una etapa de formació decisiva per a les noies adolescents que volen assolir l'excel-lència, realitat que anirem desbrossant a través dels seus principals protagonistes: els (o les) tècnics i les esportistes.

\section{Resultats de la investigació}

Presentarem només els resultats més rellevants.

Respecte al primer objectiu, conèixer els aspectes que més influeixen en la millora de les jugadores de tennis durant l'etapa semiprofessional, presentarem els següents resultats.

- La importància de tenir una molt bona relació és més alt en les jugadores actives que no pas en les retirades.

- $\quad$ Respecte al suport tècnic durant els partits, les jugadores actives necessiten més del suport tècnic que les jugadores retirades.

- En les jugadores actives els feedbacks de caràcter positiu són més freqüents que en les jugadores retirades. La majoria reben les correccions durant i després de l'execució.

- En les jugadores actives hi ha un $\mathbf{8 6 , 3 6 \%}$ dels seus tècnics que respecten el moment adient per fer els comentaris postpartit. El percentatge és molt similar al de les retirades.

- Respecte a la concentració, més o menys hi ha el mateix percentatge de jugadores actives i retirades que els hi costa mantenir la concentració. La principal causa es l'estat anímic.

- Respecte al suport psicològic, les jugadores actives tenen un percentatge més alt en quan a l'existència del psicòleg respecte a les retirades. L'opció més freqüent és la de tenir psicòleg un dia per setmana arribant a un percentatge del $90,91 \%$.

El segon objectiu: verificar l'evolució del tennis femení al llarg de les dues dècades. 
- En les jugadores retirades, la majoria de vegades era el mateix tècnic qui feia de preparador físic.

- Podem confirmar un augment de la importància de la preparació física en les jugadores actuals, desenvolupada per especialistes, concretament un $89,28 \%$ de les jugadores compten amb la figura del preparador físic.

- El treball compensatori es treballa actualment amb més freqüència que en anys anteriors.

A continuació presentem la variació dels components al llarga dels últims 20 anys.

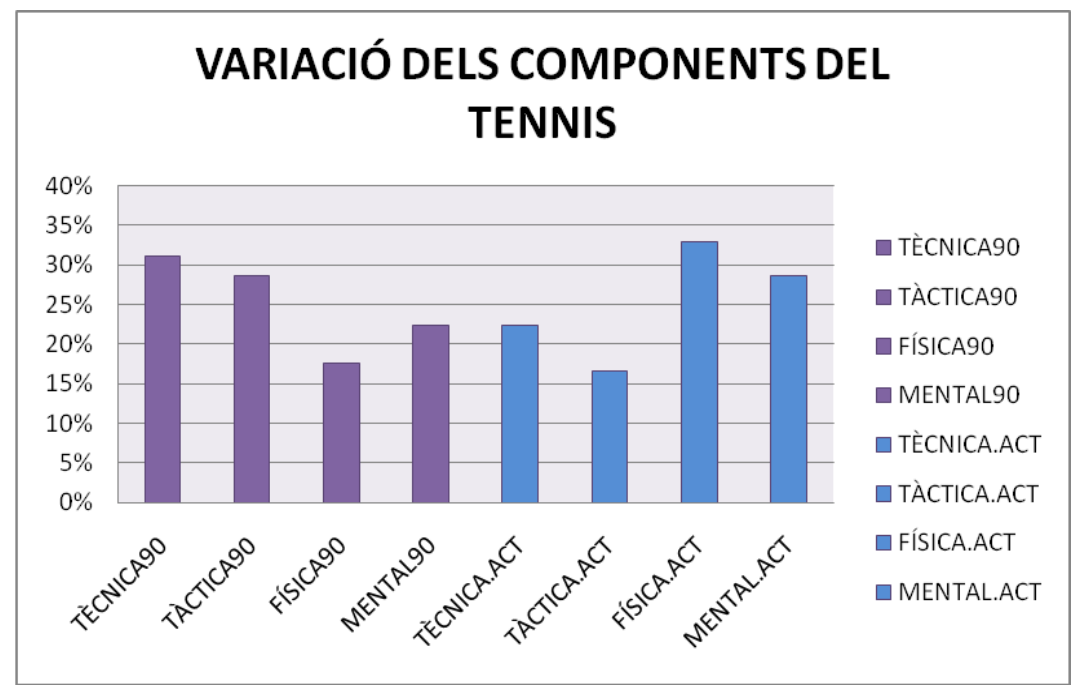

Taula 1. Variació dels components.

- Podem concloure com a dada important, que és el component físic el considerat pels tècnics com aquell que té més importància en el tennis actual i a la vegada, el que ha anat adquirint més protagonisme amb el pas dels anys. Aleshores i tenint en compte les dades anteriors, cal ressaltar la importància de fer una bona preparació física el més individualitzada possible per arribar a assolir la màxima eficàcia en cadascuna de les jugadores.

Els resultats del tercer objectiu: conèixer les causes de la manca de referents o models en el nostre país.

- Així doncs, entre els principals motius d'abandonament per part de les jugadores, un $\mathbf{2 8 , 5 7 \%}$ pels estudis, atesa la dificultat que comporta compaginar els estudis amb l'esport d'alt rendiment $i$ els desplaçaments 
continus que aquest esport implica. Si a més a més, no arriben els resultats previstos, aleshores apareix el desencant i tot seguit l'abandonament. Un percentatge idèntic a l'anterior, és a dir, un $\mathbf{2 8 , 5 7 \%}$ és degut a les lesions; com molt bé sap tothom l'aparició de les lesions generen sobretot desmotivació i desil.lusió, arribant fins i tot a provocar l'abandonament de l'activitat física. Un $\mathbf{2 3 , 8 1 \%}$ deixa l'esport d'alt rendiment per aquesta falta d'il.lusió esmentada anteriorment; manca d'il.lusió que pot venir provocada per motius de diversa índole, alguns d'ells ja anomenats. Per últim amb un percentatge menor, concretament d'un $\mathbf{4 , 7 6 \%}$, és degut a la manca de projecció, és a dir, arriba un moment en què per molt que s'entreni ja no es millora; aquest Ilindar que impedeix avançar pot ser de tipus físic, psíquic d'altres i és un dels principals motius que pot motivar el fet de deixar la competició.

- Amb relació al tipus de motivació, hem trobat com a resultat més significatiu la necessitat de la motivació intrínseca per poder mantenir-se dins del circuit professional.

- $\quad$ Respecte a la manca de jugadores classificades en top 20.

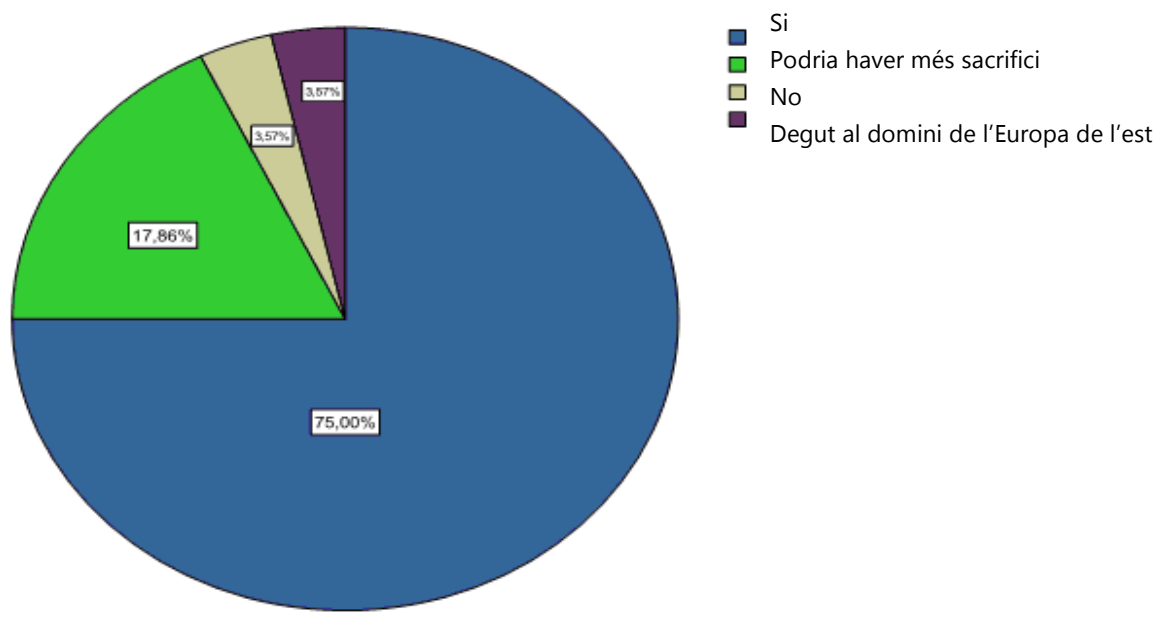

Gràfica 6.88. Hi ha manca de sacrifici?

La majoria dels tècnics, és a dir, un $\mathbf{7 5 \%}$ opinen que certament hi ha una manca de sacrifici per part de les jugadores. Un $\mathbf{1 7 , 8 6 \%}$ opina que sí que hi ha sacrifici, però que en caldria encara més. En un percentatge de 3,57\% estan els que creuen que el problema no és la manca de sacrifici de les nostres jugadores si no l'aparició de les jugadores de l'Europa de l'Est caracteritzades per grans envergadures i una condició física impressionant. 


\section{Conclusions}

- Mes de la meitat dels tècnics del nostre estudi donen participació a les seves jugadores en el seu camí d'aprenentatge, la única condició és que el tècnic va controlant tot el procés.

- Les jugadores son conscients de que necessiten mantenir una bona relació amb els seus entrenadors, fet que sabem és molt important en les noies.

- Actualment el suport tècnic que reben les jugadores actives durant els partits és superior al que rebien temps enrere. Podria dir-se que la raó està en la societat actual que tendeix a sobreprotegir als joves en general.

- El tipus de feedback més utilitzat és el positiu i el moment que més apareix és durant i després de l'execució de l'exercici.

- La majoria dels entrenadors intenten trobar el moment adient per fer l'anàlisi després del partit ja que d'aquesta manera es reforça els aspectes més positius de la jugadora i ajuda a corregir les seves errades.

- Hi ha moltes tennistes que reben l'entrenament psicològic pel mateix tècnic, les raons son vàries, entre d'altres podem senyalar la manca de pressupost de la jugadora per a fer front a aquest servei.

- Les tècniques més usades per treballar la concentració són: les rutines, la visualització i la focalització. La majoria de les jugadores usen les rutines en els tres moments importants d'un partit.

- La meitat dels tècnics del nostre estudi respecten els paràmetres d'intensitat i volum intentant que siguin el més semblants a la realitat. En efecte, com més semblant sigui l'entrenament al partit real més fàcil serà per a la jugadora fer aquesta transferència cap al joc real.

- Només una quarta part dels tècnics intenten fer una programació conjunta dels quatre components del esport estudiat.

- Referent a la preparació física, només una quarta part dels tècnics la fan de manera individual intentant respectar les característiques de cadascuna de les jugadores.

- En el nostre estudi, el preparador físic treballa amb l'equip tècnic de forma més regular que respecte a anys enrere i la freqüència $d$ 'intervenció setmanal també és més alta.

- Respecte a la freqüència de la preparació física, la majoria de les jugadores actives del nostre estudi la fan diàriament amb el seu preparador físic.

- Recordem que el treball compensatori té la funció d'evitar lesions i mantenir el cos en perfectes condicions per quan la jugadora deixi la competició. Un $59,09 \%$ el fan amb una freqüència de dos o tres cops per setmana. 
- Una dada a millorar és que un $22,73 \%$ no fan treball compensatori o només quan apareix un lesió.

- La variació dels components de l'esport del tennis han anat variant en aquestes dues últimes dècades. Així doncs, veiem que el component tècnic era el més important en la dècada dels anys 90 passant actualment a ser el tercer en importància. El component tàctic que ocupava el segon lloc en la dècada anterior actualment ocupa la última posició, el component físic que abans ocupava la última posició ara ocupa el primer lloc i per últim el component mental que abans ocupava el tercer lloc actualment ocupa el segon lloc per darrere del component físic.

- Per manca de pressupost alguns tècnics treballen en solitari amb la seva jugadora. Un terç de les jugadores de l'estudi tenen un equip tècnic al seu voltant. L'equip tècnic més freqüent està format per: I'entrenador, l'espàrring i el preparador físic.

- La quarta part dels tècnics del nostre estudi tenen una preferència per l'entrenament femení, la resta els hi es igual entrenar nois que a noies.

- Gairebé tots els entrenadors coincideixen en que la millor motivació que ha de tenir una jugadora per mantenir-se en el circuit professional ha de ser la combinació entre la motivació extrínseca i la intrínseca, amb un domini més alt de la intrínseca.

- És cert que falten models o referents al nostre país però en canvi, últimament hi ha un volum més gran que abans de jugadores situades entre les 100 millors del món. Els motius d'aquesta manca de jugadores situades en les primeres posicions és per la manca de tècnics femenins, per la manca de jugadores competitives i per la manca de treball del component estratègic. En efecte, el nostre tennis no pot ser només basat en la força i la potència si no que hem d'ampliar-lo amb els recursos tàctics. A més recursos més opcions de poder trencat el joc de la contrincant.

- Un altra conclusió, segons els entrenadors del nostre estudi, és que s'hauria d'entrenar de manera diferent als nois que a les noies.

- Els tècnics han de respectar el ritme d'evolució de cada jugadora, ja que per no complir els terminis d'edat i nivell establerts, la jugadora ja deixi de tenir opcions per aconseguir una bona classificació.

\section{Notes}

${ }^{1}$ Abril 2006 Jornada de tennis femení a San Cugat, Gener 2008 Congrés de tennis femení a Oviedo i Abril 2009 Jornada tècnica de tennis en les instal-lacions del Club tennis Barcelona. 